\title{
RESPONSABILIDADE SOCIAL CORPORATIVA: REFLEXÕES SOB A ÉGIDE DO PENSAMENTO DE PAULO FREIRE
}

\author{
Joysi Moraes \\ Doutora em Administração \\ Universidade Federal Fluminense Volta Redonda - RJ - Brasil \\ jmoraes@id.uff.br http://orcid.org/0000-0003-0133-1111
}

\section{RESUMO}

Neste ensaio, o objetivo é discutir a abordagem dominante da responsabilidade social corporativa sob a égide do pensamento de Paulo Freire, orientado pela racionalidade substantiva. Realizamos, primeiro, algumas considerações acerca das racionalidades que orientam a ação humana. A seguir, apresentamos algumas breves considerações acerca da responsabilidade social corporativa (RSC), estabelecendo um diálogo entre a concepção dominante e a perspectiva freireana, indicando que, se a RSC for tomada na perspectiva da vantagem competitiva, se revela como uma estratégia que, na perspectiva de Paulo Freire, é assistencialista e pode levar à imobilização do ser humano. A perspectiva freireana aponta que, para ir além da RSC, apenas como estratégia do capital, os sujeitos devem atuar como coautores e corresponsáveis por qualquer ação que diga respeito às suas vidas. Portanto, não pode haver dicotomia, onde alguns são 'sujeitos' da ação socialmente responsável, enquanto outros são 'objetos' desta ação. Isto é, a RSC, sob a égide do pensamento freireano, tem início quando um sujeito deixa de olhar para outro como uma categoria abstrata e o vê como pessoa; quando um sujeito cessa de fazer gestos piedosos e adota uma ação concreta e histórica, onde não há 'objeto' de uma ação, mas sujeitos em ação para transformar a realidade.

Palavras-chave: Paulo Freire. Perspectiva freireana. Responsabilidade social corporativa. Transformação social.

\section{CORPORATE SOCIAL RESPONSIBILITY: REFLECTIONS UNDER THE AEGIS OF PAULO FREIRE'S THOUGHT}

\begin{abstract}
The aim of this essay is to discuss the dominant approach to corporate social responsibility under the aegis of Paulo Freire's thought, guided by substantive rationality. First, we carry out some observations on rationality that guide human action. Then, we present some brief considerations about corporate social responsibility (CSR) establishing a dialogue between the dominant conception and the Freirean's perspective, indicating that if the CSR is taken in the view of competitive advantage, it reveals itself as an assistentialist strategy that may lead to the immobilization of the human being, from the perspective of Paulo Freire. He believes that to go beyond CSR as a strategy of capital, the subjects must act as co-authors and co-responsible for any actions concerning their lives. Therefore, there can be no dichotomy, where some people are 'subjects' of socially responsible action, while others are 'objects' of this action. That means, the RSC, under the aegis of Freire's thought, begins when a person stops looking to others as an abstract category and see her/him as a person; when a person stops doing merciful gestures and adopt a concrete and historic action, where there's not an 'object' of an action but 'subjects' acting to transform reality.
\end{abstract}

Key words: Corporate social responsibility. Freirean perspective. Paulo Freire. Social transformation.

Data da submissão: 05/07/2019

Data de aceite: 10/10/2019 


\section{INTRODUÇÃO}

Nenhum tema é apenas o que aparece na forma lingüística que o expressa. Há sempre algo mais oculto, mais profundo, cuja explicitação se faz indispensável à sua compreensão geral. Escrever sobre um tema implica em buscar, tanto quanto possível, romper as aparências enganosas que podem conduzir-nos a uma distorcida visão do mesmo. Isto significa que temos de realizar o esforço difícil de desembaraçá-lo destas aparências para apanhá-lo como fenômeno dando-se numa realidade concreta (Freire, 2007, p. 113).

É esta nossa intenção: refletir acerca da responsabilidade social corporativa (RSC) à luz da perspectiva freireana, buscando, tanto quanto possível, romper as aparências enganosas que podem conduzir-nos a uma visão distorcida do que entendemos ou deveríamos entender acerca deste constructo. Ressaltamos, a priori, que não discutiremos, neste texto, todo o aporte epistemológico que tem legitimado a práxis da RSC. O objetivo é discutir a abordagem dominante da RSC, sob a perspectiva de Paulo Freire, orientada pela racionalidade substantiva. Para tanto, primeiro são abordadas, brevemente, as racionalidades propostas por Weber (1999), segundo a compreensão de Guerreiro Ramos (1983), isto é, as racionalidades que orientam as diferentes esferas da vida.

De maneira específica, é enfatizada uma análise mais crítica da RSC que, se tomada na perspectiva da vantagem competitiva, revela-se como uma estratégia assistencialista que pode levar à imobilização do ser humano (Freire e Souza, 2008) Nestes termos, compreende-se o porquê de Corrêa e Medeiros (2003, p. 195) afirmarem que as estratégias da RSC “[...]impossibilitam ações sociais transformadoras e duradouras. No máximo, elas apaziguam problemas sociais de forma superficial e limitada, no tempo e no espaço, pois uma empresa de qualquer forma - mesmo que socialmente responsável - têm impacto social”.

Sob a lógica freireana, qualquer que seja a ação humana, como a ação socialmente responsável implementada pelas corporações, acontece dentro de determinado contexto. Deste modo, faz-se necessário avançar, primeiro, no que diz respeito a conhecer a própria realidade para entender o contexto no qual se dá a ação. Isto posto que "[...]ninguém luta contra as forças que não compreende, cuja importância não mede, cujas formas e contornos não discerne" (Freire, 2008, p. 46). Isto é, “[...]a única maneira de ajudar o homem a realizar sua vocação ontológica, inserir-se na construção da sociedade e na direção da mudança social, é substituir a captação mágica da realidade por uma captação mais e mais crítica" (Freire, 2008, p. 60).

Em outras palavras, sob a égide da perspectiva freireana, para ir além da RSC como estratégia organizacional, meramente para obter vantagem competitiva, os sujeitos devem atuar como coautores ou corresponsáveis por qualquer ação que diga respeito às suas próprias vidas e, não, alguns assumirem-se como 'sujeitos' da ação socialmente responsável em uma determinada organização e, outros, como 'objetos' dessa ação. Enfatizamos que a verdadeira RSC, na perspectiva freireana, tem início quando um sujeito deixa de olhar para outro como uma categoria abstrata e o vê como pessoa, em muitas ocasiões, injustamente tratado e privado de direitos mínimos; quando um sujeito cessa de fazer gestos piedosos e sentimentais e age em colaboração com o outro.

Para a construção do texto, apresentamos, inicialmente, algumas considerações acerca das racionalidades que orientam a ação humana. A seguir, discutimos sobre a responsabilidade social corporativa, estabelecendo um diálogo entre a concepção dominante e a perspectiva freireana. Por fim, apresentamos algumas considerações finais, seguidas das referências citadas ao longo do texto.

\section{BREVES CONSIDERAÇÕES ACERCA DAS RACIONALIDADES QUE ORIENTAM A AÇÃO HUMANA}


"Gosto de ser gente porque a história em que me faço com os outros e de cuja feitura tomo parte é um tempo de possibilidades e não de determinismo. Daí que insista tanto na problematização do futuro e recuse sua inexorabilidade" (Freire, 1996, p. 58-9). Como fazemos nossa história? Como tomamos parte? Como guiamos nossas ações, em um tempo de possibilidades e não de determinismo? Estas são perguntas fundamentais para Paulo Freire. A resposta freireana é que guiamos nossas ações, de modo substancial, sob a égide da racionalidade substantiva. Por este motivo, a primeira seção deste texto trata, ainda que de modo breve, sobre as racionalidades. A saber, a racionalidade é um dos temas fundamentais para a construção e análise de conceitos importantes no âmbito dos estudos da gestão, além de ser um dos pontos centrais da teoria weberiana e que, a longa data, vem orientando as práticas organizacionais, portanto, também, as práticas empresariais. Nesse sentido, a reflexão proposta passa, a priori, pelas considerações dos tipos de racionalidade propostas por Weber (1999) e (re)significadas por Guerreiro Ramos (1983), o que poderá nos levar, possivelmente, a uma melhor compreensão da lógica que guia o pensamento de Paulo Freire.

Faz-se importante destacar que é central para Weber (1999) entender como as pessoas orientam suas ações, especificamente a ação social, ou seja, uma conduta que se orienta pelas ações de outros, isto posto que a ação seja sempre "em relação" e em um dado campo de forças. Nesse caso, há que se saber que essas ações são orientadas por quatro tipos de racionalidades: prática, teórica, formal e substantiva. Ressalta-se, ainda, que, embora a ação possa ser mais orientada por uma determinada racionalidade do que por outra, elas não são excludentes ou se dão de forma "pura" em cada situação.

Para Weber (1999), a racionalização foi o que viabilizou a 'transformação' da sociedade prémoderna em sociedade moderna, entendida a racionalidade como um processo que é destinado à obtenção de metas dentro de um limite determinado por condições e regras. Trata-se, portanto, uma ação considerada racional na medida em que representa o meio mais adaptado para definir objetivos e que a coerência em relação a eles se traduza na exigência de um mínimo de esforços para atingilos (Prestes Motta e Pereira, 1980). Isto é, o que distingue uma ação racional de uma ação nãoracional é sua coerência com relação aos fins visados.

Kalberg (1980) salienta que os tipos de racionalidade se firmam em relações de meio e fim e com ações de valor racional, orientando tanto os modelos de processos das sociedades quanto os modos de ver o mundo e as maneiras de vida dos indivíduos. Desse modo, o processo de racionalização pode ser encontrado em diferentes esferas de vida, da política à religião, da economia à ética, e, assim por diante. A seguir, os quatro tipos de racionalidade sob a lógica weberiana (Kalberg, 1980; Weber, 1999):

$\mathrm{Na}$ racionalidade prática, o indivíduo vê e julga as atividades do mundo em relação aos seus interesses puramente pragmáticos e egoístas. Isto é, o indivíduo aceita a realidade dada, avalia as dificuldades a ele apresentadas, em relação aos seus interesses, e define o meio mais eficiente para atingir o fim visado, sem considerar a expectativa externa. Na organização, esse é o cálculo dos interesses e das vantagens para superar os obstáculos organizacionais rotineiros tornando-a mais eficiente. É a capacidade do indivíduo para a ação racional meio-fim que determina a racionalidade prática.

Na racionalidade formal, o indivíduo também se baseia em relações meios-fins, mas aqui, a questão central é a utilidade econômica e, portanto, devem ser consideradas as expectativas externas e não, apenas, o cálculo dos interesses individuais. "Uma gestão econômica é formalmente racional na medida em que a previdência essencial em toda economia racional, pode exprimir-se e, de fato, se exprime em considerações de caráter numérico e calculável" (Weber, 1999, p. 52). A racionalidade formal relaciona as esferas da vida e a estrutura de dominação que adquiriu fronteiras específicas e delineadas somente a partir do processo de industrialização, onde se estabeleceu, significativamente, a forma burocrática de dominação que se legitima pelas regras, leis e regulações. Portanto, a racionalidade formal tende a aumentar em uma sociedade onde a economia é

Revista de Gestão Social e Ambiental - RGSA, São Paulo, v. 13, n. 3, p. 98-115, set./dez. 2019. 
dominada pelo alto grau de tecnicismo e pelas leis do 'mercado', pois a meta é atingir os objetivos dentro de uma realidade, também, prática e pragmática.

Na racionalidade teórica, já se percebe outra orientação quanto à percepção da realidade, pois esta não é tomada como passível de compreensão somente a partir da ação. Isto é, ao invés de somente utilizar a ação para compreender a realidade, também são utilizados conceitos abstratos de pensamento que permitem dedução e indução lógica, atribuição de causalidade, bem como a formação de significados simbólicos. De acordo com Kalberg (1980), Weber estava convencido que um confronto teórico com a realidade poderia tanto implicar na retomada de posicionamento dos pensadores/teóricos, quanto introduzir novas regras nas ações já existentes, ou seja, novas regularidades nas ações sociais. É essa racionalidade teórica que mostra o nível de desenvolvimento intelectual de uma sociedade, pois tem em si o efeito de ser transformadora e de permitir, ainda que sob determinadas circunstâncias, a compreensão do mundo (Kalberg, 1980).

Por último, a racionalidade substantiva, que não tem como base de solução dos problemas, simplesmente, o cálculo puro dos meios-fins, não prioriza as relações meios-fins, mas se baseia nas relações passadas, presentes ou nos valores potencialmente postulados. Esse tipo de racionalidade existe como uma manifestação da capacidade inerente do homem de agir racionalmente com base em valores. Segundo Kalberg (1980), somente a ação sob a égide da racionalidade substantiva transforma a ação em si e introduz uma maneira de vida metódica, uma ação ética no mundo. A racionalidade substantiva pode ser identificada em alguns valores, tais como lealdade, compaixão, assistência mútua, justiça, igualdade, amizade, liberdade, entre outros. Tratam-se, portanto, de valores abstratos que ultrapassam qualquer indivíduo e sociedade, e que podem ser considerados para o todo.

Guerreiro Ramos (1983, p. 38-41), de forma assertiva e apropriada, sucintamente, aponta que as ações humanas são orientadas pelas racionalidades funcional e substantiva. Isto é, quem se orienta por uma racionalidade funcional "[...]não aprecia, propriamente, a qualidade intrínseca das ações, mas seu maior ou menor concurso, numa série de outros, para atingir um fim preestabelecido, independentemente do conteúdo que possam ter as ações". Atos ou elementos são funcionalmente racionais quando, articulados ou relacionados com outros atos ou elementos, contribuem para que se logre atingir um objetivo predeterminado. É em função do objetivo preestabelecido que se afere esse tipo de racionalidade. Porém, quem se orienta pela racionalidade substantiva tem a vida humana como centro de sua finalidade, ou seja, "[...]é estreitamente relacionada com a preocupação em resguardar a liberdade". Assim, "[...]é substancialmente racional todo ato intrinsecamente inteligente, que se baseia num conhecimento lúcido e autônomo de relações entre fatos".

Em suma, a ação racional, no tocante aos fins, é sistemática, consciente, calculada, atenta ao imperativo de adequar condições e meios a fins, deliberadamente, eleitos; é a ação racional que orienta a ação administrativa; é a ação orientada pela racionalidade funcional. A ação racional no tocante aos valores, por sua vez, é portadora de consciência sistemática de sua intencionalidade e é indiferente aos resultados, sendo orientada por um critério transcendente: a liberdade humana; é a ação orientada pela racionalidade substantiva.

O que se percebe, na realidade histórica, é uma combinação dessas racionalidades orientando o agir humano, sob as mais diversas perspectivas. Embora, se verifique a predominância de um tipo de racionalidade em cada ação humana. No âmbito das organizações empresariais, notadamente, há a predominância da racionalidade funcional. Portanto, há que se esperar que, no domínio das ações oriundas da responsabilidade social corporativa (RSC), também, se constate a predominância da racionalidade funcional.

No pensamento freireano, ao contrário, o que se dá, notadamente, é o predomínio da racionalidade substantiva. Isto posto, o pensamento freireano tem a vida humana como centro de sua finalidade e a liberdade como palavra-chave. É um pensamento imerso na crença de que valores, tais como lealdade, compaixão, assistência mútua, justiça, igualdade, amizade, liberdade, solidariedade, amor pelo homem e pela própria existência humana, transformam a ação do próprio

Revista de Gestão Social e Ambiental - RGSA, São Paulo, v. 13, n. 3, p. 98-115, set./dez. 2019. 
homem e introduzem a ação ética no mundo. A perspectiva freireana, neste sentido, é, fortemente, orientada pelo critério transcendente que caracteriza a ação sob a égide da racionalidade substantiva: o próprio homem e sua liberdade.

\section{A RESPONSABILIDADE SOCIAL CORPORATIVA (RSC): UM DIÁLOGO ENTRE A CONCEPÇÃO DOMINANTE E A PERSPECTIVA FREIREANA}

Normalmente, quando discutimos acerca da RSC, sugerimos a possibilidade de uma organização empresarial colaborar para transformar uma dada realidade, em termos da melhoria dos seus indicadores socioeconômicos, o que implicaria em incrementar a qualidade de vida de determinada comunidade. Essa transformação não ocorre como mágica, ao contrário, faz-se necessário que o ser da práxis, ou seja, aquele sujeito ou organização que pode executar um ato comprometido com a sociedade, de fato, o faça. "É exatamente esta capacidade de atuar, de transformar a realidade, de acordo com finalidades propostas pelo homem, associada à sua capacidade de refletir, que o faz um ser da práxis" (Freire, 1983, p. 17). Nestes termos, se compreendemos que uma organização consiste no agrupamento deliberado de pessoas que atuam para atingir um fim específico, com estrutura própria e cujas ações são coordenadas, a RSC, também, pode ser analisada sob a perspectiva freireana, posto que é uma ação de seres da práxis (pessoas), portanto, de sujeitos capazes de refletir sobre o seu 'fazer', seja de atuação e realização ou de imobilismo e apatia.

Todavia, para analisar a RSC, ou pelo menos, sua concepção dominante, sob a égide do pensamento freireano, faz-se necessário compreender que, para Freire (1982; 2008), ação e reflexão são constituintes inseparáveis do modo humano e consciente de existir.

Existir ultrapassa viver, porque é mais do que estar no mundo. É estar nele e com ele. E é essa capacidade ou possibilidade de ligação comunicativa do existente com o mundo objetivo, contida na própria etimologia da palavra, que incorpora ao existir o sentido de criticidade que não há no simples viver (Freire, 1982, p. 48).

Melhor dizendo, o existir pleno, necessariamente, reconhece a existência do outro como sujeito, não como objeto. Por esse motivo, para Paulo Freire, há um distanciamento entre solidariedade e assistencialismo. Enquanto a primeira busca modificar a realidade e o processo dáse pela participação ativa dos sujeitos, o último, transforma a pessoa em "[...] ]objeto passivo, sem possibilidade de participar do processo de sua própria recuperação" (Freire, 2008, p. 65).

Neste caso, na perspectiva freireana, ser socialmente responsável significa ser solidário, mas uma solidariedade verdadeira, expressa no trabalho para a transformação da realidade objetiva (Freire, 2000; 2005). Por conseguinte, a verdadeira RSC, no entendimento de Paulo Freire, tem início quando um sujeito deixa de olhar o outro como uma categoria abstrata e o vê como pessoa, em muitas ocasiões, injustamente tratado e privado de direitos mínimos. Assim, a ação dos sujeitos verdadeiramente comprometidos com transformação social, segundo Freire (2007, p. 47), se dá no sentido de "[...]trabalhar com, jamais sobre os indivíduos, a quem consideram sujeitos e não objetos[...]" sobre os quais incidem suas ações. Logo, na abordagem freireana, não há um "agente da mudança" porque esta é tarefa de todos que, realmente, se comprometem com a transformação social.

A autêntica RSC, portanto, pressupõe algo mais que prestar assistência, mantendo as pessoas atadas à mesma posição de dependência (Freire, 2005). De nada vale um tipo de RSC que mantém inalterada a realidade histórica dos sujeitos. A RSC legítima exige, para utilizar uma expressão notadamente freireana, que o compromisso social não venha de alguém que quer assistir ou ajudar outro através de um mecanismo arbitrário que torna o assistido um objeto da ajuda (Freire, 1985). Nestes termos, na perspectiva freireana, a verdadeira RSC põe em prática ações cujo objetivo é a mudança estrutural (Freire, 1983).

Revista de Gestão Social e Ambiental - RGSA, São Paulo, v. 13, n. 3, p. 98-115, set./dez. 2019. 
$\mathrm{Na}$ mesma direção, examinar a RSC, à luz da abordagem freireana, implica, a priori, discorrer sobre o que alguns dos principais estudiosos da temática compreendem como responsabilidade social corporativa. A princípio, destacamos que um dos conceitos muito utilizados da RSC é o do Banco Mundial (World Bank, 2020) que versa sobre o compromisso perene dos empresários com a ética, o comportamento ético e a contribuição para o desenvolvimento econômico, melhorando, de forma simultânea, a qualidade de vida dos seus colaboradores, de suas famílias, da comunidade local e da sociedade.

No entanto, de acordo com Carroll (1979), o conceito de responsabilidade social corporativa consta na literatura acadêmica desde 1930. Embora, o trabalho de Howard R. Bowen, de 1953, "Social Responsibilities of the Businessman", seja considerado a obra seminal, por muitos estudiosos da temática (Carroll, 1979; Doucin, 2011, Freguete, Nossa e Funchal, 2015). Para Bowen (1953), grandes empresas são centros vitais de poder e tomada de decisão e suas ações impactam a vida das pessoas, o que gera uma fonte de tensão na sociedade. Essa tensão acontece quando se reconhece a existência de classes sociais, portanto, de uma minoria abastada que contrata o trabalho de uma maioria desfavorecida.

Foi deste ponto de vista que Bowen $(1953$, p. 6) assinalou que a RSC se refere às obrigações dos empresários de seguir políticas, tomar decisões ou agir em termos dos objetivos e valores da sociedade. Em consonância com este argumento, McGuire (1963), Elbing e Elbing (1967) e Litz (1996) assinalam que, com posições proeminentes e poderosas na sociedade, as empresas deveriam aceitar as obrigações sociais e as responsabilidades decorrentes da sua condição. A ideia já continha o germe dos atuais objetivos da RSC: a contribuição dos empresários para com o desenvolvimento socioeconômico dos seus colaboradores, famílias, comunidade local e sociedade.

Ressalta-se que, de acordo com Doucin (2011, p. 5), "Social Responsibilities of the Businessman", de Howard R. Bowen, foi escrito a pedido do Conselho Federal das Igrejas de Cristo na América. Isto é, os fundadores da RSC, provavelmente, “[...]foram motivados por suas crenças religiosas e buscavam aliviar o sofrimento em sua alma. Era uma minoria rica vivendo do trabalho de pessoas pobres. Portanto, qualquer trabalho social teria o objetivo de aliviar sua consciência".

Certamente, faz-se necessário considerar o contexto histórico e, inclusive, geográfico, de onde foram lançadas as primeiras sementes da RSC. Isto posto que, como afirma Freire (2008, p. $30)$, “[...]num primeiro momento a realidade não se dá aos homens como objeto cognoscível por sua consciência crítica[...]", isto é, pelo menos a princípio, o sujeito faz uma aproximação espontânea do mundo, "[...]não é uma posição crítica, mas uma posição ingênua. A este nível espontâneo, o homem ao aproximar-se da realidade faz simplesmente a experiência da realidade na qual ele está". Se essa consciência é ingênua, alguns fatos históricos podem não ser percebidos em essência. Por isso "[...]a conscientização implica em ultrapassar a esfera espontânea de apreensão da realidade para chegar a uma esfera crítica, na qual a realidade se dá como objeto cognoscível e na qual o homem assume uma posição epistemológica".

Em outros termos, no que se tratava da práxis da RSC, foi uma aproximação, no mínimo, ingênua ou astutamente ingênua da realidade, uma vez que, cada vez mais, se revela como parte importante da manutenção do atual sistema de produção. Práxis, para Freire (2008, p. 30), significa a unidade indissolúvel entre ação e reflexão sobre o mundo. "A conscientização é, neste sentido, um teste de realidade. Quanto mais conscientização, mais se 'desvela' a realidade, mais se penetra na essência fenomênica do objeto, frente ao qual nos encontramos para analisá-lo". Isto é, quanto mais se estuda e se analisa o fenômeno da RSC mais se desvela sobre o próprio mundo do trabalho e mais se compreende sobre a questão do conflito crônico existente entre a organização e o indivíduo, uma vez que, na realidade, esse é um conflito inerente às relações capital-trabalho (Guerreiro Ramos, 1983).

Importa que, a partir do livro de Bowen (1953), o conceito de RSC alcançou maturidade e vem evoluindo, com foco tanto nos objetivos empresariais quanto nos interesses dos stakeholders, com o entendimento que as organizações são entes fundamentais na sociedade e que, também, devem contribuir de diversas maneiras. Para Carroll (2015), em sua formulação moderna, a RSC é 
um produto do período pós-Segunda Guerra Mundial, especialmente da década de 1960, com as mobilizações em prol de interesses sociais coletivos que contemplassem os direitos civis, as mulheres, o meio ambiente, bem como os direitos dos consumidores. Os movimentos sociais daquele período, também, exigiram das empresas respostas às suas demandas, que vieram sob o manto da RSC. Um conceito global que tem se tornado cada vez mais importante para as organizações à medida que os stakeholders e a sociedade, de um modo geral, deixam claro que as empresas devem fazer mais do que buscar obter lucros e obedecer à lei (Carroll, 2015). Notadamente simbólico do interesse institucionalizado das empresas na RSC, foi a fundação, em 1992, da Business for Social Responsibility (BSR, 2020), uma organização global sem fins lucrativos, cuja missão é trabalhar com empresas para construir um mundo justo e sustentável, a partir da criação de estratégias e soluções sustentáveis de negócios.

Assim, ao longo das últimas décadas, verifica-se que empresas cujos negócios têm um grande componente de interesse público, paulatinamente, devem se comprometer, cada vez mais, a promover atividades corporativas que, também, tragam benefícios econômicos, sociais e ambientais para a sociedade (Wang et al., 2015). Ter que responder à pressão pública e às expectativas sociais concorrem para que o próprio conceito da RSC esteja em contínua evolução. No final da década de 1970, Carroll (1979) definia a RSC como as responsabilidades integradas dos negócios que englobam economia, expectativas legais, éticas e discricionárias que a sociedade tem das organizações em um determinado momento. Anos depois, ratificou sua definição e destacou que estas responsabilidades econômicas, legais e éticas e discricionárias não são mutuamente exclusivas, mas, geralmente, se sobrepõem substancialmente entre si (Schwartz, Carroll, 2003). Lussier (2000), Ferrell e Geoffrey (2000) entendiam a RSC apenas como o comportamento da organização em relação ao cumprimento das obrigações legais da empresa. Para McWilliams e Siegel (2001), RSC são ações que parecem promover algum bem social, além dos interesses da empresa e do que é necessário fazer por lei. Daft (2003) e Vogel (2004) já sugerem que a RSC é uma extensão dos negócios; não se trata, apenas, de atender às regulamentações legais. Maignan, Ferrell e Ferrell (2005), Peters e Mullen (2009), Wang et al., (2012), Torres, Bijmolt, Tribó e Verhoef (2012), por sua vez, definem a RSC como uma espécie de investimento em atividades de cunho social que não estão, necessariamente, vinculadas à estratégia da organização, mas que, no longo prazo, podem colaborar para melhorar o seu desempenho.

Uma proposição cada vez mais corroborada por estudiosos da área, ao comprovarem, a partir de pesquisas empíricas, que a RSC melhora a eficácia operacional e o processo de desenvolvimento de novos produtos; influencia positivamente nas avaliações da marca, da empresa e na lealdade dos clientes; que as expectativas dos consumidores quanto à RSC afetam sua decisão de compra (Green e Peloza, 2014; Dell'Atti et al., 2017; Klimkiewicz e Oltra, 2017; Story, Castanheira e Hartig, 2016; Bernal-Conesa, Nieves Nieto e Briones-Pealver, 2017; Supanti et al., 2015; Rangan, Chase e Karim (2015); Bhardwaj et al. (2018), Ferrell, Harrison, Ferrell e Hair, 2019). A literatura mostra que as empresas que atuam de maneira socialmente responsável têm melhor reputação, obtêm maior apoio dos consumidores e funcionários e dispõem de menor custo de capital (Goss e Roberts, 2011; El Ghoul et al., 2011; Mason e Simmons, 2013; Cheng, Ioannou e Serafeim, 2014; Cahan, Chen, Chen e Nguyen, 2015; Du et al., 2015; Galego-Álvarez, Formigoni e Antunes, 2014; Chen, Zhou e Zhu, 2019; Rivera, Bigne e Curras-Perez, 2019). Benlemlih e Bitar (2018), ainda, ressaltam que empresas com alto nível de RSC desfrutam de baixa assimetria de informações, alta solidariedade das partes interessadas e, principalmente, um alto envolvimento com a RSC proporciona redução de investimentos ineficientes e, consequentemente, aumento da eficiência do investimento.

Nestes termos, a RSC tornou-se um ponto de inflexão para as organizações, haja vista que seu desempenho em RSC, também, recebe grande atenção da mídia de massa, dos fundos de investimento socialmente responsáveis e de organizações que as classificam quanto ao nível de responsabilidade social e que podem afetar sua reputação e operações (Di Giuli e Kostovetsky, 2014; McCarthy, Oliver e Song, 2017; Chen, Zhou e Zhu, 2019).

Revista de Gestão Social e Ambiental - RGSA, São Paulo, v. 13, n. 3, p. 98-115, set./dez. 2019. 
No entanto, embora os estudos sobre o tema tenham se intensificado, levando à crescente literatura sobre RSC, verifica-se o registro de diversos significados para o termo, resultando na falta de consenso, pelo menos entre os acadêmicos, sobre o conceito de RSC (Hopkins, 2003; Richter, 2010; Edmans, 2011; Deng et al., 2013; Servaes e Tamayo 2013; Galego-Álvarez, Formigoni e Antunes, 2014; Flammer, 2015; Ferrell et al., 2016; Frynas e Yamahaki, 2016; Ferrell et al., 2016; Liang e Renneboog, 2017; Bansal e Song, 2017; Choi et al., 2018; Silveira e Petrini, 2018; Hoi, Wu e Zhang, 2018; Latif e Sajjad, 2018; Rivera, Bigne e Curras-Perez, 2019; Duque, Silva e Cohen, 2019).

Provavelmente, esse dissenso tem sua origem na forma como acontece a própria evolução do constructo. Teoria e prática da RSC têm sido construídas de modo utilitarista e, muitas vezes, verifica-se a elaboração de uma teoria distanciada da prática organizacional (Melo Neto e Fróes, 2001; Bittencourt e Carrieri, 2005; Aramburu e Antunes, 2007; Vasconcelos, Alves e Pesqueux, 2012; Ometto, Bulgacov e May, 2015).

Freire (1978), neste sentido, entende que a institucionalização de um conceito só se efetiva quando há verdadeira unidade entre teoria e prática. Nesse aspecto, ressalta que, a unidade entre teoria e prática não elimina o exame aprofundado e a reflexão crítica sobre a própria prática. Para Freire $(1978 ; 2005)$, o que faz a unidade entre teoria e prática é pôr o contexto teórico em contato com a dimensão do contexto concreto. Freire (2005, p. 14-2) lembra que os homens são seres do quefazer porque seu fazer é ação e reflexão. É práxis. "E, na razão mesma em que o quefazer é práxis, todo fazer do quefazer tem de ter uma teoria que necessariamente o ilumine. O quefazer é teoria e prática. É reflexão e ação. Não pode reduzir-se nem ao verbalismo, nem ao ativismo". Em outros termos, se há compromisso verdadeiro para com a construção de um mundo justo e sustentável, como afirma a Business for Social Responsibility (BSR, 2020), urge, também, uma teoria da ação transformadora. Por este motivo, Freire (2005) defende a práxis, a teoria do fazer, e rejeita a dicotomia onde há uma etapa para reflexão e outra para ação. No entanto, se a análise crítica reflexiva sobre a realidade e suas contradições

[...]evidencia a impossibilidade imediata de uma forma determinada de ação ou a sua inadequacidade ao momento. Desde o instante, porém, em que a reflexão demonstra a inviabilidade ou a inoportunidade de uma forma tal ou qual de ação, que deve ser adiada ou substituída por outra, não se pode negar a ação nos que fazem esta reflexão" (Freire, 2005, p. 146).

Sob a perspectiva freireana, este processo, também, faz parte da construção de um conceito que elucida, que explica, exatamente, do que se trata determinado constructo.

Conquanto, apesar da falta de consenso sobre a definição de RSC, são diversos os autores que buscam compatibilizar na mesma descrição 'obter, sustentar e aumentar os fins lucrativos empresariais, bem como providenciar o desenvolvimento socioeconômico para melhoria da qualidade de vida da população' (Carroll e Shabana, 2010; Beattie e Smith, 2013; Erhemjamts, Li e Venkateswaran, 2013; Bocken et al., 2014; Wesselink et al., 2015; Knorringa e Nadvi; 2016; Melo et al., 2019). Em outras palavras, "[...]no geral, esse campo cresceu, significativamente, e, hoje, contém uma grande proliferação de teorias, abordagens e terminologias" (Campos et al., 2019). Todavia, duas correntes teóricas se destacam.

A primeira, a visão conservadora ou neoclássica, cujo argumento central é a geração de lucro. O investimento em responsabilidade social por parte das empresas só é válido se for parte do negócio da empresa (Friedman, 1962; 1970). Premissa compartilhada por Jensen (1988), dado que o autor entende que a função principal da empresa é gerar valor para o acionista e, neste caso, os investimentos devem proporcionar algum tipo de retorno à empresa (aos acionistas), caso contrário não são justificados. Para a perspectiva neoclássica, indivíduos e organizações têm direito e liberdade de decidir onde e como investir seus recursos; mas não lhes é facultado o direito de investir o que não lhes pertences. No caso das empresas, os gestores devem zelar pelos recursos dos 
acionistas. Mas se decidem aplicá-los em práticas de responsabilidade social, estariam reduzindo os lucros dos acionistas em prol de causas que não são axiais para a organização. Conforme esta corrente, a RSC só pode ser promovida se estiver vinculada à estratégia organizacional, ou seja, como fonte de geração de vantagem competitiva (Mcwilliams e Siegel, 2001; Freedman e Stagliano, 1991; Godfrey, 2005; 2009; Lee, 2008; Porter e Kramer (2006); Aguilera et al., 2007). Esta perspectiva entende que práticas de RSC fazem parte do rol de estratégias que viabilizam melhorar a imagem da organização que, no longo prazo, resultará em uma série de benefícios, diretos ou indiretos, para as empresas, devido à vinculação com causas sociais (Lichtenstein et al., 2004; Luo e Bhattacharya, 2006; Ellen et al., 2006; Nan e Heo, 2007; Pivato et al., 2008; Swaen e Chumpitaz, 2008; Vlachos et al., 2009; Andrade et al., 2010; Stanaland et al., 2011; Du et al., 2011; 2015; Mandhachitara e Poolthong, 2011; Melo e Galan, 2011; Garrido, Cunha e Cavalcante, 2014).

Sob a perspectiva freireana, a visão neoclássica da RSC sequer pode ser compreendida como responsabilidade social corporativa. As premissas e critérios para sua promoção são impeditivos da concretização de ações autênticas de RSC que têm como prioridade o ser humano. A RSC, na visão neoclássica personifica, simplesmente, mais uma estratégia que pode providenciar ganhos de competitividade empresarial. Para ir além da RSC como mera estratégia organizacional, Freire $(2005 ; 2008)$, acredita que os sujeitos devem atuar como corresponsáveis por qualquer ação que diga respeito às suas próprias vidas e não a empresa ou aqueles que atuam em seu nome. No caso de implementação desta dicotomia, ou seja, da criação de 'sujeitos' da ação socialmente responsável e de 'objetos' dessa ação, o que se verifica é o assistencialismo, ações paliativas que, provavelmente, produzirão apenas algum tipo de benefício para a organização.

Segundo Freire $(2005 ; 2008)$, se a mudança se dá a partir de um polo de decisão que se situa fora ou longe do sujeito, ele é, simplesmente, 'objeto' da ação de outros, um dependente, um "serpara-o-outro". Se a mudança se dá a partir do próprio sujeito ou, pelo menos, com sua participação ativa, ele atua como 'sujeito' verdadeiro da ação, um ser da práxis, age como um "ser-para-si”. Nesse sentido, a primeira questão a ser colocada por organizações que pretendem ser socialmente responsáveis é a da própria realidade que priva os homens do direito de ser homens, questionar sua própria posição de subalternos na sociedade. Nas palavras de Freire (2008, p. 87), uma RSC autêntica deveria discutir com os sujeitos por quais motivos "[...]eles não são homens à margem da estrutura, mas homens oprimidos no interior desta mesma estrutura[...]", as razões pelas quais “[...]não podem superar sua dependência incorporando-se à estrutura que é responsável por esta mesma dependência".

Para Freire (2008), se aceitamos e propagamos que o 'objeto' da ação socialmente responsável é uma pessoa que existe à margem da sociedade, somos conduzidos a considerá-lo como uma espécie de "homem doente" e a RSC um medicamento que pode permitir seu retorno à estrutura "sadia" da qual havia se separado. Todavia, seria necessário reconhecer que tal 'separação' é resultado de um processo historicamente construído.

Assim, adotar uma posição freireana significa questionar a própria história do ser humano, o sistema de produção, as formas de dominação, seus significados e contribuições para nossa atual condição histórica. Portanto, esperar que a RSC tenha o homem como centro de sua ação e a transformação social como resultado do seu trabalho, em parceria com estes mesmos homens, implica em contar com a boa vontade das empresas. O que não parece realístico, posto que, pelo menos, sob o ponto de vista neoclássico da RSC, o objetivo maior das empresas é a geração de lucro. Logo, seria "[...] ]esperar uma solução feliz, vinda das operações de resgate do Estado capitalista, o que seria uma grande ilusão" porque a natureza ontológica do Estado é proteger a classe que o forja e sustenta (Mészáros, 2009, p. 25).

A segunda corrente teórica em destaque é a da visão liberal, percebida como mais progressista e de vanguarda. Samuelson (1971) é um dos expoentes, cujos argumentos apontam que a empresa não deve 'apenas se envolver' em práticas socialmente responsáveis; na realidade, deve promovê-las e liderá-las, posto que, também, utiliza os recursos disponíveis na sociedade. Nesta abordagem, as empresas devem assumir a responsabilidade pelas consequências de suas decisões e

Revista de Gestão Social e Ambiental - RGSA, São Paulo, v. 13, n. 3, p. 98-115, set./dez. 2019. 
ações na sociedade, devem ir além das exigências legais, técnicas e econômicas (Davis, 1960; 1967; 1973; Samuelson, 1971; Litz, 1996; Carroll, 1999). Nesta corrente, também, pode ser incluído Archie Carroll, cuja classificação, em categorias, das ações de RSC realizadas pelas empresas, tem sido largamente utilizada: econômica (devem produzir bens e serviços para atender os consumidores, ao mesmo tempo que produzem benefícios financeiros, portanto, lucros para si); legal (devem promover suas atividades fins e enquadrar-se nos códigos e normas instituídos, obedecendo à legislação em vigor); ética (devem atender às expectativas dos consumidores por meio de condutas que não estão, necessariamente, descritas na forma de lei, como costumes, normas e valores sociais, ou seja, respeitar os códigos relacionais implícitos); e filantrópica (devem desenvolver trabalhos voluntários ou que não tragam nenhum retorno ou benefício esperado pela empresa, ações de cunho estritamente voluntário). De fato, o que se verifica nas práticas das empresas é uma combinação de implementação destas categorias, por vezes, com predominância de uma ou outra (Carroll, 1979; Irigaray, Vergara e Santos, 2013; Irigaray, Vergara e Araújo, 2017).

No limite, como aponta o Instituto Ethos (2020), as empresas buscam promover a estabilidade social, fundamental para que continuem operando e os consumidores adquirindo bens e serviços. Neste sentido, Nilsson (2009), Melo e Galan (2011), Stanaland et al., (2011) e Garrido, Cunha e Cavalcante (2014) destacam que, apesar das discordâncias em relação às motivações da RSC, os objetivos sociais e empresariais não podem ser percebidos como antagônicos ou conflitantes. Se, de um lado, a organização não apresentar desempenho financeiro suficiente, não haverá investimentos em ações sociais (Ellen et al., 2006). Porém, se, por outro lado, a RSC for apenas instrumental, um discurso vazio, converter-se-á em uma fraude retórica (Brownet et al., 2006; Christensen, Morsing e Thyssen, 2010). Du et al. (2010) buscam resolver o problema assinalando que as ações de RSC podem ser percebidas como um jogo de soma positiva, onde empresas e sociedade obtêm ganhos.

Sob a égide do pensamento de Paulo Freire e, objetivamente, sob a lógica empresarial, a RSC tem grande valor do ponto de vista utilitarista e instrumental, seja do ponto de vista conservador (neoclássico) ou liberal (progressista). Na realidade, a principal diferença entre estas correntes da RSC está no fato que os neoclássicos declaram, sem qualquer constrangimento ou restrição, que o investimento em responsabilidade social por parte das empresas só é válido se for parte do negócio da empresa, se promover algum ganho ou benefício. Os progressistas, por sua vez, embora não declarem seu caráter utilitarista, entendem que a RSC pode produzir consequências positivas não declaradas para as empresas, caso elas decidam investir em ações socialmente responsáveis. Isto posto que, as ações organizacionais devem levar em conta que as condições materiais e históricas imprescindíveis à acumulação do capital devem ser mantidas Freire (2000; 2005; 2008). Resta à empresa atuar de modo 'socialmente responsável'

[...]apenas nos limites permitidos e absorvíveis pela relação dominante (capitaltrabalho), mas jamais no sentido de sua superação. Em última instância, transforma-se uma questão ontológica em uma questão de aperfeiçoamento do conhecimento de formas de administração, ainda que em favor das classes despossuídas, da relação capital-trabalho. (Paniago, 2007, p. 16-7).

Faz-se necessário reconhecer que não é só o trabalhador que se subordina ao capital, mas, também, o capitalista para manter sua posição, pois se tentar impor limite à autodeterminação do capital põe em risco seu negócio (Mészáros, 2002).

Desse modo, na perspectiva da racionalidade substantiva, da concepção freireana, a RSC está sujeita à relação capital-trabalho que deixa espaços somente para ações assistencialistas, de manutenção do status quo. Tudo pode mudar, desde que todos permaneçam comportando-se conforme a expectativa social vigente, ou seja, sem reverter as condições, nem quebrar a estabilidade do sistema, pois, assim, mantém-se o equilíbrio social, 'mudando' para tudo permanecer no mesmo (Lampedusa, 1961).

Revista de Gestão Social e Ambiental - RGSA, São Paulo, v. 13, n. 3, p. 98-115, set./dez. 2019. 
Para Freire (2000), essa postura das empresas, percebidas como progressistas, na realidade, revela-se como um método que a lógica do sistema encontrou para permitir algumas concessões e, ao mesmo tempo, manter o status quo. Isto é, sob o pretexto de promover melhorias para pessoas ou comunidades, a RSC, também, contribui para aprofundar e legitimar o abismo entre classes. E não poderia ser diferente, pois, na perspectiva freireana, a concretização da autêntica RSC pressupõe ações cujo propósito é a transformação da realidade objetiva. Esta, por sua vez, só acontece por meio da conscientização dos sujeitos, o que inviabiliza a materialização de uma legítima RSC. Isto porque, na opinião de Freire (2008), uma verdadeira ação socialmente responsável por parte das corporações levaria à denúncia de uma estrutura injusta na qual as empresas ocupam uma posição dominante.

Em Freire (2005, p. 33), a estrutura e a ordem social injustas são fontes geradoras, permanentes, das ações socialmente responsáveis da corporação, da sua 'generosidade'. Uma generosidade que não ultrapassa a si mesma, garantindo, assim, os papéis de necessitados e salvadores; perpetuando a dicotomia entre sujeitos e objetos das ações socialmente responsáveis das empresas. Uma das características destas formas de ação é o manejo das massas populares ao darlhes a impressão que as ajuda, quando, de fato, as mantêm dependentes das políticas e práticas da RSC. Esta espécie de dominação quase nunca é percebida, mesmo por profissionais sérios, mas ingênuos, que se deixam envolver. Tal ablepsia é fruto da ênfase em uma visão focalista dos problemas e não na percepção deles como dimensão de uma totalidade (Freire, 2005, p. 161). Estas formas focalistas de ação dificultam a percepção crítica da realidade e colaboram para que, mesmo profissionais sérios, acreditem que estão contribuindo com outros sujeitos.

Por este motivo, profissionais que implementam a RSC devem ter lucidez sobre seu propósito e suas práticas, pois eles determinam seu papel e seus métodos de ação. Se a opção é conservadora, ação e métodos se orientarão no sentido de frear quaisquer transformações sociais. A tendência será a de adotar soluções de caráter assistencialista (Freire, 2007, p. 45) que, por sua vez, "[...]conduzirão à sacralização da ordem social, que não permite ser tocada nem discutida" (Freire, 2007, p. 119). Se, por outro lado, a opção é progressista e o compromisso é com a verdadeira RSC, ação e métodos se orientarão no sentido de "[...]atuar com e não sobre[...]" os seres humanos, trabalhar e conscientizar para que transformem a realidade objetiva (Freire, 1983, p. 20). Em outras palavras, na perspectiva freireana, a RSC autêntica não se utiliza de "[...]práticas que costumamos chamar de 'ações anestesiadoras' ou de 'ação aspirina', expressões de um idealismo subjetivista que só pode levar à preservação do status quo" (Freire, 2007, p. 124). A ilusão de que, com obras humanitárias e com o desenvolvimento de uma racionalidade desgarrada do mundo é possível transformá-lo, existe apenas naqueles que chamamos de 'inocentes' ou 'espertos'. No entanto, para Freire (2007), os de fato 'inocentes' não se sabem inocentes ou ingênuos, mas por meio da sua própria prática histórica se descobrem como tal e podem superar sua ingenuidade; os 'espertos', por sua vez, sabem muito bem que, com tais formas de ação, retardam o processo fundamental que é, na verdade, o da transformação da sociedade, com a instauração de uma nova prática social.

Assim, torna-se cada vez mais imperativo criar soluções para problemas gerados pelo próprio sistema do capital, portanto, pelas próprias corporações. Alternativas cujos fracassos são inevitáveis, em razão dos próprios limites do capital, como a RSC, sob muitos aspectos, posto que é limitada pelo próprio capitalista e tem servido, majoritariamente, apenas como paliativo (Mészáros, 2009). Em outros termos, a RSC, sob a égide da perspectiva freireana, apresenta-se como um anódino para a sociedade.

\section{CONSIDERAÇÕES FINAIS}

A literatura apresenta, com fartura, evidências sobre os efeitos positivos da RSC nas organizações. São diversos os estudos que documentam o quão fecundo pode ser o seu impacto no valor da empresa e, ao mesmo, é notória a ênfase no aspecto estratégico da RSC, como que buscando estimular sua adoção pelas empresas e legitimar os ganhos financeiros e benefícios

Revista de Gestão Social e Ambiental - RGSA, São Paulo, v. 13, n. 3, p. 98-115, set./dez. 2019. 
oriundos da sua implementação. Em outras palavras, a RSC é apresentada como um imperativo econômico e estratégico para as empresas, devido à vantagem competitiva que pode propiciar, demasiadamente anunciada nos textos acadêmicos.

Por outro lado, a natureza abrangente desses ganhos e benefícios sugere que a RSC é uma atividade multifacetada e uma construção multidimensional, sujeita a interpretações e usos variados, por diversos grupos de interesse e em diferentes contextos institucionais. E, exatamente, neste cenário, argumenta-se que, ao ser socialmente responsável, uma empresa pode, simultaneamente, aumentar seu valor de mercado e promover o desenvolvimento socioeconômico da sociedade de forma igualitária. Tal é a crença nesta possibilidade, que disciplinas 'de' e 'sobre' RSC são incorporadas aos currículos, no ensino superior, com o propósito de conscientizar os estudantes quanto à necessidade de proporcionar melhores condições sociais para as pessoas, criando um mundo mais justo e sustentável para todos, pelas práticas de RSC.

Na perspectiva freireana, a partir dos argumentos do mainstream da responsabilidade social corporativa, alicerçados em pesquisas empíricas, tais práticas organizacionais sequer podem ser consideradas como RSC autêntica, pois não passam de estratégias organizacionais cujo objetivo é providenciar ganhos de competitividade empresarial. A RSC, à luz da abordagem freireana, tem a vida humana como centro de sua finalidade, o ser humano como prioridade e a transformação da realidade como objetivo. Nesses termos, os resultados das políticas e práticas do que se verifica como corrente predominante da RSC, na área de Administração, são ações assistencialistas, paliativos que, provavelmente, deverão produzir algum tipo de benefício para a organização.

Por outro lado, sob a égide do pensamento freireano, o ser humano deve ser tomado como meio e como fim de qualquer ação que o tenha como razão de existir. Em outros termos, não são as ações de alguns grupos, ainda que bem intencionados, que transformarão a realidade daqueles que são ‘objeto' das ações socialmente responsáveis das corporações. Para começar, o 'objeto' destas ações deveria fazer parte do processo de elaboração projeto que tem como propósito transformar sua realidade. O que se observa, na perspectiva de Paulo Freire, é que a RSC não se resume, simplesmente, a ações esporádicas, onde o ser humano é meio para atingir fins organizacionais, tampouco a ações assistencialistas, pois estas, ainda que regulares, continuam a ser assistencialistas. Portanto, são um fim em si mesmas, pois mantêm a possibilidade de as corporações perpetuarem a dicotomia entre 'sujeitos' e 'objetos' das ações socialmente responsáveis das empresas.

Como sugestão para trabalhos futuros, indica-se a realização de estudos empíricos, no sentido de verificar se as reflexões e ilações aqui apresentadas, sob a égide do pensamento de Paulo Freire, são justificadas ou não. Sugere-se, ainda, estudos que verifiquem quais práticas e/ou ações da RSC mais utilizadas pelas empresas estão alicerçadas na racionalidade instrumental, bem como quais práticas e/ou ações da RSC, minimamente, não se apoiam no cálculo puro dos meios-fins, ou seja, são concretizadas com base na racionalidade substantiva, portanto, sob a perspectiva freireana.

Recomenda-se, também, a realização de estudos que procurem verificar em que momento e por qual motivo as organizações tomaram a decisão de adotar a RSC como uma de suas políticas e práticas organizacionais. Da mesma forma, seria oportuna a realização de pesquisas que revelassem os resultados concretos da RSC para aqueles que são 'objetos' e/ou 'sujeitos' das ações socialmente responsáveis das corporações.

\section{REFERÊNCIAS}

Aguilera, R., Rupp, D., Williams, C., e Ganapathi, J. (2007). Putting the S back in corporate social responsibility: a multilevel theory of social change in organizations. Academy of Management Review, 32, 836-863.

Andrade, M. A. M. et al., (2010). Valor de marca e responsabilidade social em siderúrgicas mineiras e a percepção de suas comunidades de entorno. Enanpad, 34, Anais... Anpad, Rio de Janeiro (RJ). 
Aramburu, J. V., e Antunes, E.D.D. (2007). A responsabilidade social empresarial no século XXI: a perspectiva ética está sendo contemplada? Encontro Nacional sobre Gestão Empresarial e Meio Ambiente, 9. Curitiba (PR).

Bansal, P., Song, H. C. (2017). Similar but not the same: differentiating corporate sustainability from corporate responsibility. Academy of Management Annals, 11(1), 105-149.

Beattie, V., Smith, S. (2013). Value creation and business models: refocusing the intellectual capital debate. The British Accounting Review, 45(4), 243-254.

Benlemlih, M., Bitar, M. (2018). Corporate social responsibility and investment efficiency. Journal of Business Ethics, 148(3), 647-671.

Bernal- Conesa, J. A., Nieves Nieto, C., \& Briones- Pealver, A. J. (2017). CSRstrategy in technology companies: its influence on performance, competitiveness and sustainability. Corporate Social Responsibility and Environmental Management, 24, 96-107.

Bhardwaj, P. et al. (2018). When and how is corporate social responsibility profitable? Journal of Business Research, 84, 206-219.

Bittencourt, E., Carrieri, A. (2005). Responsabilidade social: ideologia, poder e discurso na lógica empresarial. Revista de Administração de Empresas, 45 (Edição Especial MG), 10-22.

Bocken, N. M. P., Short, S. W., Rana, P., Evans, S. (2014). A literature and practice review to develop sustainable business model archetypes. Journal of Cleaner Production, 65, 42-56.

Bowen, H. R. (1953). Social Responsibilities of the Businessman. New York: Harper \& Row.

Brown, T. J., et al. (2006). Identity, intended image, construed image, and reputation: an interdisciplinary framework and suggested terminology. Journal of the Academy of Marketing Science, 34, 99-106.

BSR (2020). Business for Social Responsibility. Our story: building the business of a better world. Recuperado em fevereiro de 2020, de: https://www.bsr.org/en/about/story

Campos, S. A. P., et al., (2019). Caminhos teóricos e metodológicos da pesquisa em responsabilidade social corporativa: retratos da publicação brasileira. Desafio Online 7(3), 528-552.

Carroll, A. B. (1979). A three-dimensional conceptual model of corporate performance. Academy of Management Review, 4(4), 497-505.

Carroll, A. B. (1999). Corporate social responsibility: evolution of a definitional construct. Business and Society, 38, 268-295, September.

Carroll, A. B., Shabana, K. M. (2010). The business case for corporate social responsibility: a review of concepts, research and practice. International Journal of Management Review, 2010, 12, 85-105.

Carroll, A. B. (2015). Corporate social responsibility: the centerpiece of competing and complementary frameworks. Organizational Dynamics, 44, 87-96.

Cahan, S.F., Chen, C., Chen, L., Nguyen, N.H. (2015). Corporate social responsibility and media coverage, Journal of Banking and Finance, 59, 409-422.

Chen, W., Zhou, G., Zhu, X. (2019). CEO tenure and corporate social responsibility performance, Journal of Business Research, 95(C), 292-302.

Cheng, B., Ioannou, I., Serafeim, G. (2014). Corporate social responsibility and access to finance, Strategic Management Journal, 35, 1-23.

Choi, J.J. et al. (2018). Business groups and corporate social responsibility. Journal of Business Ethics, 153 (4), 931-954. 
Christensen, L. T., Morsing, M., Thyssen, O. (2010). The polyphony of corporate social responsibility. In: Cheney, G.; May, S.; Munshi, D. (Ed.). Handbook of communication ethics. Hillsdale: Lawrence Erlbaum, 457-474.

Corrêa, F. T. B. S., e Medeiros, J. R. C. (2003). Responsabilidade social corporativa para quem? In: Instituto Ethos. Responsabilidade social das empresas: a contribuição das universidades. (1 ed.) São Paulo: Petrópolis, 2, 151-199.

Daft, R. L. (2003). Organization theory and design. Cincinnati: South-Western College Publishing.

Davis, K. (1960). Can business afford to ignore social responsibilities? California Management Review, 2, 70-76.

Davis, K. (1967). Understanding the social responsibility puzzle: what does the businessman owe to society? Business Horizons, 10, 45-50.

Davis, K. (1973). The case for and against business assumption of social responsibilities. Academy of Management Journal, 16, 312-322.

Dell'Atti, S., Trotta, A., Iannuzzi, A. P., Demaria, F. (2017). Corporate social responsibility engagement as a determinant of bank reputation: an empirical analysis. Corporate Social Responsibility and Environmental Management, 24(6), 589-605.

Deng et al. (2013). Corporate social responsibility and stakeholder value maximization: evidence from mergers. Journal of Financial Economics, 110(1), 87-109.

Di Giuli, A., Kostovetsky, L. (2014). Are red or blue companies more likely to go green? Politics and corporate social responsibility. Journal of Financial Economics, 111(1), 158-180.

Doucin, M. (2011). Corporate social responsibility - Private self-regulation is not enough. Private Sector Opinion - World Bank, 24, 1-16.

Du, et al. (2010). Maximizing business returns to corporate social responsibility (CSR): The role of CSR communication. International Journal of Management Review, 12(1), 8-19.

Du, et al. (2011). Corporate social responsibility and competitive advantage: Overcoming the trust barrier. Management Science, 57, 1528-1545.

$\mathrm{Du}$, et al. (2015). Corporate social responsibility, multi-faceted job-products, and employee outcomes. Journal of Business Ethics, 131(2), 319-335.

Duque, L. P., Silva, J. F., Cohen, M. (2019). Impactos da responsabilidade social corporativa no desempenho de indústrias: teste empírico nas operadoras brasileiras de planos de saúde e odontológicos. Revista Ibero-Americana de Estratégia, 18(2), 188-204.

Edmans, A. (2011). Does the stock market fully value intangibles? Employee satisfaction and equity prices. Journal of Financial Economics, 101, 621-640.

Elbing, A.O., Elbing, C.J. (1967). The value issue of business. McGraw-Hill, New York.

El Ghoul at al. (2011). Does corporate social responsibility affect the cost of capital? Journal of Banking and Finance, 35, 2388-2406.

Ellen P. S., Webb D. J., Mohr L. A. (2006). Building corporate associations: consumer attributions for corporate socially responsible programs. Journal of the Academy of Marketing

Science, 34(2), 147-157.

Erhemjamts, O., Li, Q., Venkateswaran, A. (2013). Corporate social responsibility and its impact on firms' investment policy, organizational structure, and performance. Journal of Business Ethics, 118(2), 395-412.

Ferrell, O. C., Geoffrey, H. (2000). Business: a changing world. New York: McGraw-Hill. 
Ferrell, O.C., Harrison, D., Ferrell, L., Hair, J. (2019). Business ethics, corporate social responsibility, and brand attitudes: an exploratory study. Journal of Business Research, 95, 491501.

Ferrell, et al. (2016). Socially responsible firms. Journal of Financial Economics, 122(3), 585-560.

Flammer, C. (2015). Does corporate social responsibility lead to superior financial performance? A regression discontinuity approach. Management Science, 61(11), 2549-2568.

Freire, P. (1978). Cartas à Guiné-Bissau: registros de uma experiência em processo. Rio de Janeiro: Paz e Terra.

Freire, P. (1983). Educação e mudança. Rio de Janeiro: Paz e Terra.

Freire, P. (1985). Educação e Mudança. Rio de Janeiro: Paz e Terra.

Freire, P. (1996). Pedagogia da autonomia: saberes necessários à prática educativa. São Paulo: Paz e Terra.

Freire, P. (2000). Pedagogia da indignação: cartas pedagógicas e outros escritos. São Paulo: Editora UNESP.

Freire, P. (2001). Pedagogia da esperança: um reencontro com a pedagogia do oprimido. Rio de Janeiro: Paz e Terra.

Freire, P. (2005). Pedagogia do oprimido. Rio de Janeiro: Paz e Terra.

Freire, P. (2007). Ação cultural para a liberdade. São Paulo: Paz e Terra.

Freire, P. (2008). Conscientização: teoria e prática da liberação. São Paulo: Centauro.

Freire, R., e Souza, M. J. (2008). Responsabilidade Social Corporativa: estado da arte da produção científica no exterior e no Brasil. Encontro Nacional de Gestão Empresarial e Meio Ambiente, Porto Alegre.

Freguete, L. M., Nossa, V., Funchal, B. (2015). Responsabilidade social corporativa e desempenho financeiro das empresas brasileiras na crise de 2008. Revista de Administração Contemporânea, 19(2), 232-248.

Friedman, M. (1962). Capitalism and freedom. Chicago: University of Chicago Press.

Friedman, M. (1970). The social responsibility of business is to increase its profits. New York Times Magazine, September 13.

Freedman, M., Stagliano, A. (1991). Differences in social-cost disclosures. Accounting, Auditing and Accountability Journal, 4(1), 68-83.

Frynas, J. G., Yamahaki, C. (2016). Corporate social responsibility: review and roadmap of theoretical perspectives. Business Ethics: A European Review, 25(3), 258-285.

Galego-Álvarez, I., Formigoni, H., Antunes, M. T. P. (2014). Corporate social responsibility practices at Brazilian firms. Revista de Administração de Empresas, 54(1), 12-27.

Garrido, I. G., Cunha, F. R., Cavalcante, F. M. (2014). O papel da confiança na relação entre responsabilidade social corporativa e o valor de marca. Revista de Ciências da Administração, 16(39), 101-118.

Godfrey, P. (2009). The relationship between corporate social responsibility and shareholder value: an empirical test of the risk management hypothesis. Strategic Management Journal, 45, 425-445.

Godfrey, P. (2005). The relation between corporate philanthropy and shareholder wealth: A risk management perspective. Academy of Management Review, 30, 777-798. 
Goss, A., Roberts, G. S. (2011). The impact of corporate social responsibility on the cost of bank loans, Journal of Banking and Finance, 35, 1794-1810.

Green, T., Peloza, J. (2014). How do consumers infer corporate social responsibility? The role of organization size, Journal of Consumer Behaviour, 13(4), 282-293.

Guerreiro Ramos, A. (1983). Administração e contexto brasileiro: esboço de uma Teoria Geral da Administração. Rio de Janeiro: Editora da FGV.

Hoi, C.K., Wu, Q., Zhang, H. (2018). Community social capital and corporate social responsibility. Journal of Business Ethics, 152(3), 647-665.

Hopkins, M. (2003). The planetary bargain - CSR matters. London: Earthscan.

Instituto Ethos (2020). Instituto Ethos de Empresas e Responsabilidade Social. Recuperado em fevereiro de 2020, de: https://www.ethos.org.br/

Irigaray, H., Vergara, S., Santos, M. (2013). Responsabilidade social corporativa: um duplo olhar sobre a Reduc. Revista Administração Mackenzie, São Paulo, 14(6), 82-111.

Irigaray, H., Vergara, S., Araújo, R. (2017). Responsabilidade social corporativa: o que revelam os relatórios sociais das empresas. Organizações \& Sociedade, 24(80), 73-88.

Jensen, M. (1988). Takeovers: their causes and consequences. Journal of Economic Perspectives, 2(1), 21-44.

Kalberg, S. (1980). Max Weber's types of rationality: cornerstones for the analysis of rationalization process in history. American Journal of Sociology, 85(5), 1145-1179.

Klimkiewicz, K., Oltra, V. (2017). Does CSR enhance employer attractive-ness? The role of millennial job seekers' attitudes. Corporate Social Responsibility and Environmental Management, 24(5), 449-463.

Knorringa, P., Nadvi, K. (2016). Rising power clusters and the challenges of local and global standards. Journal of Business Ethics, 133(1), 55-72.

Lampedusa, G. T. (1961). O leopardo. São Paulo: Difusão Europeia do Livro.

Latif, F. K., Sajjad, A. (2018). Measuring corporate social responsibility: a critical review of survey instruments. Corporate Social Responsibility and Environmental Management, 25, 1174-1197.

Lee, M. D. P. (2008). A review of the theories of corporate social responsibility: its evolutionary path and the road ahead. International Journal of Management Reviews, 10(1), 53-73.

Liang, H., Renneboog, L. (2017). On the foundations of corporate social responsibility. Journal of Finance, 72(2), 853-910.

Lichtenstein, D., et al. (2004). The effect of corporate social responsibility on customer donations to corporate- supported nonprofit. Journal of Marketing, 68(4), 16-32.

Litz, R. A. (1996). A resource-based-view of the socially responsible firm: stakeholder interdependence, ethical awareness, and issue responsiveness as strategic assets. Journal of Business Ethics, 15(12), 1355-1363.

Luo, X., Bhattacharya, C. (2006). Corporate social responsibility, customer satisfaction, and market value. Journal of Marketing, 70, 1-18.

Lussier, R. N. (2000). Management fundamentals. New York: Thomson Learning, Inc.

Maignan, I., Ferrell, O. C., Ferrell, L. (2005). A stakeholder model for implementing social responsibility in marketing. European Journal of Marketing, 39(9-10), 956-977. 
Mandhachitara, R., Poolthong, Y. (2011). A model of customer loyalty and corporate social responsibility. Journal of Services Marketing, 25(2), 122-133.

Mason, C., Simmons, J. (2013). Embedding corporate social responsibility in corporate governance: a stakeholder systems approach. Journal of Business Ethics, 119 (1), 77-86.

McCarthy, S., Oliver, B., Song, S. (2017). Corporate social responsibility and CEO confidence, Journal of Banking and Finance, 75, 280-291.

McGuire, J. W. (1963). Business and society. New York: McGraw-Hill.

McWilliams, A., Siegel, D. (2001). Corporate social responsibility: a theory of the firm perspective. Academy of Management Review, 26(1), 117-127.

Melo, M. F. S. et al. (2019). A relação entre responsabilidade social corporativa e competitividade: proposição de modelo teórico moderado pela participação em cadeias globais de valor. Revista Brasileira de Gestão de Negócios, 21(4), 722-739.

Melo, T., Galan, J. I. (2011). Effects of corporate social responsibility on brand value. Journal of Brand Management, 18(6), 423-437.

Melo Neto, F. P., e Froes, César. (2001). Gestão da responsabilidade social corporativa: o caso brasileiro. Rio de Janeiro: Qualitymark.

Mészáros, I. (2009). A crise estrutural do capital. São Paulo: Boitempo.

Mészáros, I. (2002). Para além do capital. São Paulo: Boitempo.

Nan, X., Heo, K. (2007). Consumer responses to corporate social responsibility (CSR) initiatives. Journal of Advertising, 36(2), 63-74.

Nilsson, J. (2009). Segmenting socially responsible mutual fund investors - the influence of financial return and social responsibility. International Journal of Bank Marketing, 27(1), 5-31.

Ometto, M. P., Bulgacov, S., May, M. R. (2015). A efetividade dos estrategistas da responsabilidade social empresarial. Organizações \& Sociedade, 22(74), 423-441.

Paniago, M. C. S. (2007). Mészáros e a incontrolabilidade do capital. Maceió: Edufal.

Peters, R., Mullen, M. R. (2009). Some evidence of the cumulative effects of corporate social responsibility on financial performance. Journal of Global Business Issues, 3(1), 1-14.

Pivato, S., et al. (2008). The impact of corporate social responsibility on consumer trust: the case of organic food. Business Ethics: a European Review, 17(1), 3-12.

Porter, M. E., Kramer, M. (2006). Strategy \& society: the link between competitive advantage and corporate social responsibility. Harvard Business Review, 84(12), 78-92.

Prestes Motta, F. C., e Pereira, L.C. B. (1980). Introdução à organização burocrática. São Paulo: Editora Brasiliense.

Rangan, K., Chase, L., Karim, S. (2015). The truth about CSR. Harvard Business Review, 93(1/2), 40-49.

Richter, U. H. (2010). Liberal thought in reasoning on CSR. Journal of Business Ethics, 97(4), 625649.

Rivera, J. J., Bigne, E., Curras-Perez, R. (2019). Efeitos da responsabilidade social corporativa na lealdade do consumidor com a marca. Revista Brasileira de Gestão de Negócios, 21(3), 395-415.

Samuelson, P. A. (1971). Love that corporation. Mountain Bell Magazine 
Schwartz, M. S., Carroll, A. B. (2003). Corporate social responsibility: a threedomain approach. Business Ethics Quarterly, 13(4), 503-530.

Servaes, H., Tamayo, A. (2013). The impact of corporate social responsibility on firm value: the role of customer awareness. Management Science, 59(5), 1045-1061.

Silveira, L. M., Petrini, M. (2018). Desenvolvimento sustentável e responsabilidade social corporativa: uma análise bibliométrica da produção científica internacional. Gestão \& Produção, 25(1), 56-67.

Stanaland, A. J. S., et al. (2011). Consumer perceptions of the antecedents and consequences of corporate social responsibility. Journal of Business Ethics, 102(1), 47-55.

Story, J., Castanheira, F., Hartig, S. (2016). Corporate social responsibility and organizational attractiveness: implications for talent management. Social Responsibility Journal, 12(3), 484-505.

Supanti, D., et al. (2015). Enhancing the employer- employee relationship through corporate social responsibility (CSR) engagement. International Journal of Contemporary Hospitality Management, 27(7), 1479-1498.

Swaen, V., Chumpitaz, R. C. (2008). Impact of corporate social responsibility on consumer trust. Recherche et Applications in Marketing, 23(4), 7-34.

Torres, A., Bijmolt, T. H., Tribó, J. A., Verhoef, P. (2012). Generating global brand equity through corporate social responsibility to key stakeholders. International Journal of Research in Marketing, 29(1), 13-24.

Vasconcelos, I. F. F. G., Alves, M. A., Pesqueux, Y. (2012). Responsabilidade social corporativa e desenvolvimento sustentável: olhares habermasianos. Revista de Administração de Empresas, 52(2), 148-152.

Vlachos, P. A., et al. (2009). Corporate social responsibility: attributions, loyalty, and the mediating role of trust. Journal of Academy of Marketing Science, 37(2), 170-180.

Vogel, D. (2004). Is there a market for virtue? A critical appraisal of corporate social responsibility. Manuscript presented at the Third Transatlantic Business Ethic Conference.

Wang, Y. G., et al. (2012). The relationship between corporate social responsibility and firm performance: an application of quantile regression. Frontiers of Business Research in China, 6(2), 218-244.

Wang, D.H.M., et al. (2015). The effects of corporate social responsibility on brand equity and firm performance, Journal of Business Research, 68, 2232-2236.

Wesselink, R., et al. (2015). Individual competencies for managers engaged in corporate sustainable management practices. Journal of Cleaner Production, 106, 497-506.

World Bank (2020). The World Bank. Corporate Responsibility. Recuperado em janeiro de 2020, de: https://www.worldbank.org/en/about/what-we-do/crinfo

Weber, M. (1999). Economia e sociedade: fundamentos da sociologia compreensiva. Brasília: Editora da Universidade de Brasília, v. 1.

RGSA adota a Licença de Atribuição CC BY do Creative Commons (https://creativecommons.org/licenses/by/4.0/) 